\title{
Secukinumab Use in Patients with Moderate to Severe Psoriasis, Psoriatic Arthritis and Ankylosing Spondylitis in Real-World Setting in Europe: Baseline Data from SERENA Study
}

\author{
Uta Kiltz - Petros P. Sfikakis · Karl Gaffney • Paul-Gunther Sator • Ralph von Kiedrowski • \\ Andreas Bounas · Nicola Gullick · Curdin Conrad • Dimitris Rigopoulos • \\ Eric Lespessailles · Marco Romanelli · Pierre-Dominique Ghislain · Jan Brandt-Jürgens • \\ Rasho Rashkov · Maher Aassi · Roberto Orsenigo · Chiara Perella · Effie Pournara • \\ Sven Gathmann · Piotr Jagiello · Justyna Veit · Matthias Augustin
}

Received: February 20, 2020 / Published online: May 6, 2020

(C) The Author(s) 2020

\section{ABSTRACT}

Introduction: Secukinumab, a fully human monoclonal antibody that directly inhibits interleukin-17A, has demonstrated robust efficacy in the treatment of moderate to severe psoriasis (PsO), psoriatic arthritis (PsA) and

Digital Features To view digital features for this article go to https://doi.org/10.6084/m9.figshare.12144837.

Electronic Supplementary Material The online version of this article (https://doi.org/10.1007/s12325020-01352-8) contains supplementary material, which is available to authorized users.

\section{U. Kiltz ( $\square)$}

Rheumazentrum Ruhrgebiet, Herne, Germany e-mail: Uta.Kiltz@elisabethgruppe.de

U. Kiltz

Ruhr-University Bochum, Bochum, Germany

P. P. Sfikakis

Joint Rheumatology Programme, National and Kapodistrian University of Athens Medical School, Athens, Greece

K. Gaffney

Norfolk and Norwich University Hospital NHS

Foundation Trust, Norfolk, UK

P.-G. Sator

Department of Dermatology, Municipal Hospital

Hietzing, Vienna, Austria ankylosing spondylitis (AS), with a rapid onset of action, sustained long-term clinical responses and a consistently favourable safety profile across phase 3 trials. Here, we report the clinical data at enrolment from SERENA, designed to investigate the real-world use of secukinumab across all three indications.

Methods: SERENA is an ongoing, longitudinal, observational study conducted at 438 sites across Europe in patients with moderate to severe plaque $\mathrm{PsO}$, active PsA or active AS. Patients should have received at least 16 weeks of secukinumab treatment before enrolment in the study.

R. von Kiedrowski

Company for Medical Study \& Service Selters

(CMS3) GmbH, Selters, Germany

\section{A. Bounas}

Olympion Therapeutirion, Patras, Greece

N. Gullick

University Hospitals Coventry \& Warwickshire NHS

Trust, Coventry, UK

C. Conrad

Centre Hospitalier Universitaire Vaudois, Lausanne, Switzerland

D. Rigopoulos

Dermatology and Venerology, Medical School, National and Kapodistrian University of Athens, Athens, Greece 
Results: Overall 2800 patients were included in the safety set; patients with PsA $(N=541)$ were older than patients with $\mathrm{PsO}(N=1799)$ and patients with AS $(N=460)$; patients with $\mathrm{PsO}$ had a higher mean body weight than patients with PsA and patients with AS; and patients with $\mathrm{PsO}$ and patients with AS were predominantly male. Time since diagnosis was longer in patients with $\mathrm{PsO}$ compared with patients with PsA and patients with AS, and about $40 \%$ of patients were either current or former smokers. The proportion of obese patients (body mass index $\geq 30 \mathrm{~kg} / \mathrm{m}^{2}$ ) was similar across indications. Patients were treated with secukinumab for a mean duration of 1 year prior to enrolment (range 0.89-1.04). The percentages of patients with prior biologics exposure were $31.5 \% \mathrm{PsO}$, $59.7 \%$ PsA and 55\% AS. The percentages of patients prescribed secukinumab monotherapy were $75 \%(n=1349)$ in $\mathrm{PsO}, 48.2 \%(n=261)$ in PsA and $48.9 \%(n=225)$ in AS groups.

Conclusion: Baseline demographics of the study population are consistent with existing literature. This large observational study across all secukinumab indications will provide valuable information on the long-term effectiveness and safety of secukinumab in the real-world setting.

Keywords: Ankylosing spondylitis; Biologics; Observational; Psoriasis; Psoriatic arthritis; Real-world; Rheumatology; Safety; Secukinumab

E. Lespessailles

Regional Hospital and University of Orleans, Orleans, France

M. Romanelli

Dermatology Department, University of Pisa,

Lungarno Antonio Pacinotti, 43, 56126 Pisa, PI, Italy

P.-D. Ghislain

Dermatology, Cliniques Saint-Luc, Université

Catholique de Louvain, Brussels, Belgium

J. Brandt-Jürgens

Rheumatologische Schwerpunktpraxis, Berlin, Germany

R. Rashkov

Department of Internal Medicine, Medical

University, Sofia, Bulgaria

\section{Key Summary Points}

Why carry out this study?

Although secukinumab has demonstrated robust efficacy in the treatment of moderate to severe psoriasis (PsO), psoriatic arthritis (PsA) and ankylosing spondylitis (AS), with a rapid onset of action, sustained long-term clinical responses, and a consistently favourable safety profile across numerous phase 3 trials there is still a need to investigate the use of secukinumab beyond the tightly controlled setting of clinical trials.

There is limited real-world evidence on long-term retention and efficacy of secukinumab in patients with moderate to severe plaque PsO, PsA or AS.

\section{What was learned from the study?}

The population recruited into SERENA reflects that of interventional trials with secukinumab. However, SERENA patients are predominantly biologic experienced and have received multiple biologics, mostly tumour necrosis factor (TNF) inhibitors.

This large observational study across all, currently approved, secukinumab indications will provide valuable information on the long-term retention, effectiveness and safety of secukinumab in the real-world setting.

M. Aassi - C. Perella · E. Pournara - S. Gathmann .

P. Jagiello

Novartis Pharma AG, Basel, Switzerland

R. Orsenigo

Novartis Farma SpA, Origgio, Italy

J. Veit

Novartis Pharma GmbH, Nuremberg, Germany

M. Augustin

Institute for Health Services Research in

Dermatology and Nursing, University Medical

Center Hamburg, Hamburg, Germany 


\section{INTRODUCTION}

Psoriasis (PsO), psoriatic arthritis (PsA) and ankylosing spondylitis (AS) are chronic immune-mediated inflammatory diseases [1]. The pathogenesis of these diseases is a complex interplay between environmental, genetic and immune triggers leading to dysregulation of the immune response [2-5]. These diseases have a profound impact on patients' health-related quality of life (HR-QoL) and are associated with many comorbidities [6-15].

PsO typically manifests as plaques that occur most commonly on the elbows and knees, but can affect any area including palms, soles, nails, scalp and genitals [16-20]. PsO has a reported prevalence of between $1.3 \%$ and $8.5 \%$ in the adult population of European countries [21]. The proportion of patients with PsO suffering from PsA has been reported to be 19.7-29\% $[22,23]$. A 90\% improvement from baseline Psoriasis Area and Severity Index (PASI) score is now defined as the threshold of treatment success as per the European Medicines Agency and a "measure of optimal response" by the American Academy of Dermatology [24, 25]. There is emerging interest in the evaluation of reduction of absolute PASI score as a better indicator of therapeutic response and the higher clinical relevance of the remaining absolute PASI score as therapeutic target (i.e. PASI score $0-1, \leq 2$, $\leq 3$ and $\leq 5)$ [26].

Spondyloarthritis (SpA) is an umbrella term for inflammatory diseases with axial and/or peripheral manifestations that involve joints, entheses and extra-articular structures including the eyes, skin and gastrointestinal system $[5,27]$. Both PsA and AS are part of the SpA spectrum of diseases which share genetic, clinical, radiological and therapeutic characteristics, classified according to the Assessment of Spondyloarthritis International Society (ASAS) and the Classification of Psoriatic Arthritis (CASPAR) classification criteria [27-29]. PsA is characterised by peripheral joint disease, enthesitis and dactylitis [30, 31]. AS is an inflammatory disease primarily affecting the axial skeleton, which may lead to spinal fusion, deformity and disability. In patients with AS, extra-articular manifestations (EAMs) such as psoriasis, acute anterior uveitis and inflammatory bowel disease may be present [32, 33]. Comorbidities include cardiovascular, pulmonary, renal and neurological involvement $[34,35]$. Prevalence of SpA has been estimated as $1.4 \%$ in the European population, with a comparable proportion of patients affected by AS and PsA, and is expected to rise with increased awareness of SpA and advances in diagnostic techniques and screening [36].

Interleukin-17A (IL-17A) is a key cytokine in the pathogenesis of $\mathrm{PsO}$ and $\mathrm{SpA}$, driving inflammation, enthesitis and structural damage. IL-17A produced by Th17 cells, mast cells and leukocytes drives tissue inflammation, keratinocyte activation and release of psoriasis-associated molecules [37-41]. The IL-17A signalling pathway is critical to bone erosion in PsA and bone fusion in AS [38, 42-45]. Secukinumab, a fully human immunoglobulin G1kappa monoclonal antibody that directly inhibits interleukin-17A, has demonstrated robust efficacy in the treatment of moderate to severe $\mathrm{PsO}$, PsA and AS, with a rapid onset of action, sustained long-term clinical responses and a consistently favourable safety profile across phase 3 trials [46-48].

In SCULPTURE and ERASURE/FIXTURE studies, PASI 75/90/100 responses with secukinumab $300 \mathrm{mg}$ were sustained from year 1 to 5 $[49,50]$. In FUTURE 2, American College of Rheumatology response criteria (ACR) 20/50 responses in $300 \mathrm{mg}$ and $150 \mathrm{mg}$ dose groups at year 1 were sustained or further improved at year 4. Secukinumab also showed sustained improvement in PASI 75/90 responses, dactylitis and enthesitis [51]. In MEASURE 2, ASAS 20/40 responses at year 1 were sustained at year 4 with $150 \mathrm{mg}$ dose [52]. Randomised controlled trials (RCTs) are the 'gold standard' for evaluating the efficacy and safety of new therapeutic molecules in a highly selective population in tightly controlled settings because this strategy reduces confounding factors. This approach however does not guarantee that the treatment in everyday clinical practice will lead to the same results. In the real world, physicians may deal with more advanced conditions, multiple comorbidities and patients 
who may not be eligible for RCTs or for whom treatment options have been exhausted. Treatment adherence and persistence in real-world patient populations can also be a challenge [53-55].

Secukinumab was approved for the treatment of moderate to severe PsO, PsA and AS in 2015 in the European Union [56]. During the past 4 years real-world data on secukinumab use has been gathered in numerous non-interventional trials [57-59], registries [60-62] and during the routine collection of post-marketing safety information. Nevertheless, there is still a need for an observational study that collects and analyses the outcomes associated with underlying disease and its comorbidities, particularly in terms of assessing long-term retention, sustainability of effectiveness, long-term safety, treatment patterns over time and impact on HR-QoL of secukinumab treatment in patients with moderate to severe plaque PsO, PsA and AS.

SERENA is a non-interventional study with an observational period of up to 5 years designed to investigate the real-world long-term use of secukinumab in patients with moderate to severe PsO, PsA or AS. We report the baseline clinical data from the overall study population collected at the time point of enrolment into the study.

\section{METHODS}

\section{Study Design}

SERENA (CAIN457A3403) is an ongoing, longitudinal, non-interventional study with prospective and retrospective collection of primary data on the retention, safety and effectiveness of secukinumab in patients with moderate to severe chronic plaque-type PsO, active PsA or active AS (Fig. 1). The SERENA study prospectively collects real-world data in patients who have previously received secukinumab for at least 16 weeks, providing valuable insights into its long-term effectiveness and tolerability in clinical practice. Published data suggests that clinical responses to secukinumab are usually achieved within 16 weeks $[46,47,63,64]$. Patients will participate in the study for a maximum of 5 years (60 months). Visits are documented every 6 months after enrolment. The study will end either when all enrolled patients (across indications) complete at least 2 years of follow-up, unless they choose

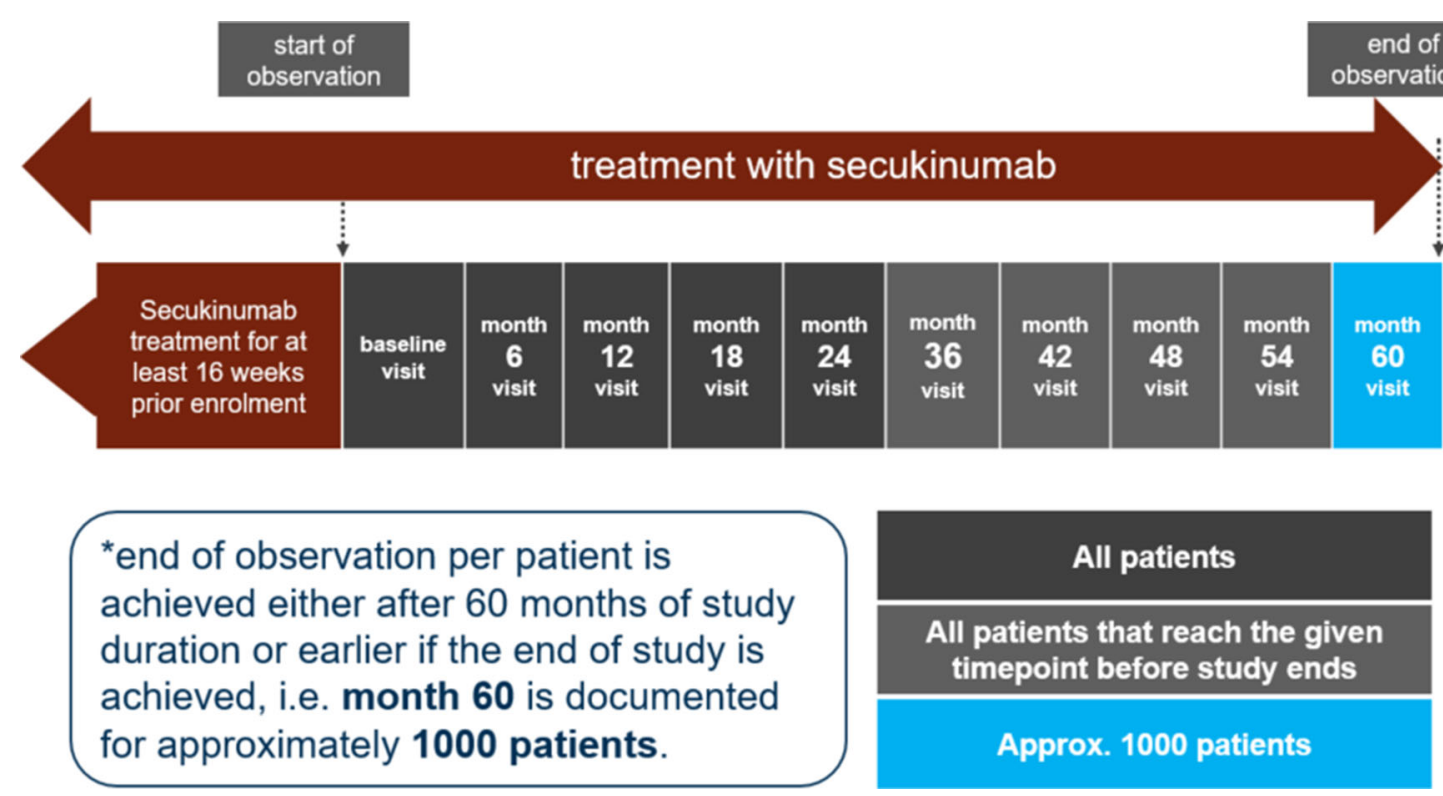

Fig. 1 Study design. Start of treatment/therapy refers to the period when patients received first dose of secukinumab. Study enrolment refers to inclusion of patients in the SERENA study (start of observation; baseline visit) 
to exit the study, or when the 5-year visit has been documented for approximately 1000 patients. The end of study will be determined by the later of these three time points, i.e. whichever occurs last. Individual patients exit the study if they discontinue secukinumab. All patients provided written informed consent before enrolling into the study. The study protocol was approved by the institutional review board of each participating centre (Supplementary Material). The trial was conducted in accordance with the Declaration of Helsinki and Good Clinical Practice (GCP) and in compliance with all federal, local or regional requirements.

\section{Patients}

\section{Inclusion Criteria}

Adult patients with a diagnosis (assessed by the treating physician) of active moderate to severe plaque $\mathrm{PsO}$, active PsA or active AS who are prescribed secukinumab according to the approved product information were included in the study. Patients should have received at least 16 weeks of commercial secukinumab treatment before registration in the study. For patients in Germany diagnosed as having active moderate to severe plaque PsO, a PASI assessment on the day of or up to 1 week prior to initial secukinumab treatment was mandatory. The decision for treatment with secukinumab had to be made regardless of this non-interventional study.

\section{Exclusion Criteria}

Patients were excluded from the study if they had any medical or psychological condition in the treating physician's opinion which may prevent the patient from study participation for the initial 2 years; participated in parallel in an interventional clinical trial or Novartis-sponsored non-interventional study generating primary data for secukinumab; were within the safety follow-up phase of a previous interventional or non-interventional trial using secukinumab as drug of interest or comparator. Initially, patients who received secukinumab as an investigational medical product during a secukinumab interventional trial any time in the past were allowed to be included into the SERENA study. After an amendment, inclusion of these patients was no longer permitted. The discontinuation of secukinumab treatment after inclusion into the study resulted in termination of observation within the study; intermediate breaks were allowed.

\section{Objectives}

The primary objective of the SERENA study is to assess the long-term retention of secukinumab treatment in routine clinical practice for the treatment of moderate to severe plaque-type $\mathrm{PsO}$, active PsA and active AS, and to identify factors affecting the retention of secukinumab treatment for the overall study population.

\section{Collected Data}

Patients enrolled to SERENA were treated according to the local label and data was collected as available in clinical routine. Data on primary and additional outcome variables were collected prospectively. Since patients included in the study were pre-treated with secukinumab, data on effectiveness and safety was also collected retrospectively from the start of the treatment.

At enrolment, patient demographics and clinical characteristics, medical and treatment history were collected. Every prior biologic treatment taken for PsO, PsA or AS was documented without a time limit; all other prior PsO, PsA or AS treatments were only documented if taken within 6 months prior to enrolment.

At enrolment, patients were assigned to the indication of moderate to severe plaque PsO, PsA or AS by the treating physician on the basis of dominant indication intended for treatment with secukinumab. This means that patients having dominant $\mathrm{PsO}$ and treated by dermatologists are documented as patients with PsO; and patients having dominant PsA or AS and treated by rheumatologists are documented as patients with PsA or AS, respectively. In addition, the dermatologists had a possibility to document, at enrolment and during the study, 
if a patient with $\mathrm{PsO}$ has been diagnosed with PsA. Depending on the documented diagnosis (or diagnoses), different effectiveness and quality of life (QoL) parameters as listed below were collected at enrolment and every 6 months for up to 5 years.

- PsO PASI [65], body surface area (BSA, where available) [66], Physician Global Assessment (PGA) [65], psoriatic nail involvement

- PSA 78 Total Joint Count (TJC) and 76 Swollen Joint Count (SJC) including dactylitis [67, 68], PGA [65], total pain visual analogue scale (VAS) [69], enthesitis assessment (Leeds Enthesitis Index, LEI) [70], X-ray assessment, PASI (not routinely performed by rheumatologists) [65], BSA (where available), psoriatic nail involvement

- $A S$ Bath AS Disease Activity Index (BASDAI) [71], patient's global assessment of disease activity using numeric rating scale (NRS) [27], C-reactive protein (CRP) and/or highsensitivity C-reactive protein (hsCRP) [72], AS Disease Activity Score (ASDAS) [71], total spinal pain VAS [73], enthesitis assessment (Maastricht Ankylosing Spondylitis Enthesitis Score, MASES) [74], X-ray and MRI assessment of spine and/or sacroiliac joints

\section{Data Analysis}

The study was initiated in October 2016 and enrolled over 2900 patients with moderate to severe PsO, PsA or AS at 438 sites in 19 countries across Europe until October 2018. This interim analysis is mainly based on descriptive statistical methods; no imputations of data in analyses were made. The following analysis sets were used for statistical analysis and presentation of data:

- Safety set: consists of patients who received at least one dose of secukinumab treatment after informed consent

- Full analysis set (FAS): consists of patients who are included in the safety set and fulfil all the inclusion criteria and none of the exclusion criteria
The FAS is considered as the primary analysis dataset and will be used for the primary and additional variables. Baseline presentations were based on the safety set and on the FAS. On the basis of the dominant indication evaluated at enrolment, patients were assigned to three cohorts: PsO, PsA and AS. In the PsO cohort, several parameters that are potential risk factors for developing PsA, e.g. nail involvement or joint involvement measured via presence of dactylitis, were in addition analysed in the subgroups of patients that did not report PsA at enrolment and those that reported additional diagnosis of PsA at enrolment. Previous treatments of PsO, PsA and AS have been analysed as previous medications taken prior to start of secukinumab and also as treatment taken concomitantly to secukinumab for the given indication, i.e. PsO, PsA or AS. Patients could receive more than one type of treatment (prior to start of secukinumab or concomitant) e.g. combinations of conventional systemic therapy with topical treatments or non-steroidal anti-inflammatory drugs (NSAIDs), or biologics with topical/NSAIDs and/or conventional systemic agents. Every prior biologic treatment taken for $\mathrm{PsO}, \mathrm{PsA}$ or AS was to be documented without a time limit, all other prior PsO, PsA or AS treatments were to be documented only if taken within 6 months prior to baseline visit.

In the prior treatment analyses, a patient was assigned to the biologic pre-treated group if she/ he was treated with any biologic drug, irrespective of the original indication the medication was given for.

Comorbid medical condition and medical history were coded using MedDRA and summarized descriptively. Medical history events that occurred after the first exposure to secukinumab and prior to informed consent were analysed for all safety events and for safety events of special interest. Total exposure was calculated as sum of all patient-years in each subgroup, from first secukinumab treatment date to informed consent date in this study. Inflammatory bowel disease (IBD), major adverse cardiovascular events (MACE) and malignant tumours were identified using Novartis MedDRA Queries (NMQs). Candida infections were any events within the Candida 
infection MedDRA High Level Term; infections were any events within MedDRA System Organ Class Infections and Infestations. Hypersensitivity and injection site reaction were identified using Standard MedDRA Query (SMQ) "Hypersensitivity".

\section{RESULTS}

\section{Disposition}

Overall, 2932 patients were enrolled across Europe (Supplementary Fig. 1) and 2800 patients were included in the safety set. Patients $(n=132)$ who did not receive at least one secukinumab injection after signing the informed consent were excluded. On the basis of the dominant indication evaluated at enrolment, patients were assigned to three cohorts: PsO $(n=1799)$, PsA $(n=541)$ and AS $(n=460)$. A majority of the patients were treated with secukinumab in non-clinical trial settings except for 320 patients in the PsO cohort.

\section{Demographics and Disease Characteristics at Enrolment}

Patients with PsA $(N=541)$ were older than patients with $\mathrm{PsO}(N=1799)$ and patients with AS $(N=460)$; and patients with $\mathrm{PsO}$ and patients with AS were predominantly male (Table 1). At enrolment, 393 (21.8\%) of patients with $\mathrm{PsO}$ also reported PsA diagnosis. patients with $\mathrm{PsO}$ had a higher mean body weight than both PsA and patients with AS. The proportion of obese patients (body mass index $\geq 30 \mathrm{~kg} / \mathrm{m}^{2}$ ) was similar across indications, reported in a total of $821(37.2 \%)$ patients (Table 1). Time since diagnosis was longer in patients with $\mathrm{PsO}$ compared with PsA and patients with AS and about $40 \%$ of all patients were either current or former smokers.

Table 1 Demographics and clinical characteristics at enrolment

\begin{tabular}{llll}
\hline Characteristic & PsO $(\boldsymbol{N}=\mathbf{1 7 9 9})$ & PsA $(\boldsymbol{N}=\mathbf{5 4 1})$ & AS $(\boldsymbol{N}=\mathbf{4 6 0})$ \\
\hline Age $\left(\right.$ years), mean $\pm \mathrm{SD}^{\mathrm{a}}$ & $48.3 \pm 13.6$ & $52.4 \pm 12.0$ & $46.1 \pm 11.5$ \\
Gender $($ male $), n(\%)$ & $1209(67.2)$ & $241(44.5)$ & $270(58.7)$ \\
Race (Caucasian), $n(\%)$ & $1687(93.8)$ & $510(94.4)$ & $434(94.3)$ \\
Body weight $(\mathrm{kg})$, mean $\pm \mathrm{SD}$ & $87.2 \pm 20.5$ & $83.4 \pm 18.0$ & $80.1 \pm 16.9$ \\
BMI $\left(\mathrm{kg} / \mathrm{m}^{2}\right)$, mean $\pm \mathrm{SD}$ & $28.7 \pm 6.1$ & $28.8 \pm 5.7$ & $27.0 \pm 5.0$ \\
Overweight, $25 \leq \mathrm{BMI}<30\left(\mathrm{~kg} / \mathrm{m}^{2}\right), n(\%)$ & $361(26.3)$ & $126(28.4)$ & $146(37.4)$ \\
Obesity, $\mathrm{BMI} \geq 30\left(\mathrm{~kg} / \mathrm{m}^{2}\right), n(\%)$ & $519(37.8)$ & $163(36.7)$ & $139(35.6)$ \\
Smoking status, $n(\%)^{\mathrm{b}}$ & & & \\
Current & $558(31.0)$ & $109(20.2)$ & $108(23.5)$ \\
Former & $242(13.5)$ & $85(15.8)$ & $63(13.7)$ \\
Never & $689(38.3)$ & $281(52.1)$ & $232(50.4)$ \\
Time (years) since disease diagnosis, mean $\pm \mathrm{SD}$ & $17.4 \pm 13.3$ & $8.7 \pm 7.9$ & $9.3 \pm 9.1$ \\
\hline
\end{tabular}

$A S$ ankylosing spondylitis, $B M I$ body mass index, $N$ total number of patients in the study population, $P s A$ psoriatic arthritis, $P s O$ psoriasis, $S D$ standard deviation

${ }^{a}$ For patients whose age was missing and only year of birth was collected, age was calculated as date of baseline year of birth - July 01

b Proportions do not add up to $100 \%$ as there were missing data or status was unknown for some patients 
Table 2 Secukinumab treatment duration prior to inclusion in the study

\begin{tabular}{llll}
\hline & PsO $(\boldsymbol{N}=\mathbf{1 7 9 9})$ & PsA $(\boldsymbol{N}=\mathbf{5 4 1})$ & AS $(\boldsymbol{N}=\mathbf{4 6 0})$ \\
\hline$n^{\mathrm{a}}$ & 1793 & 538 & 455 \\
Mean \pm SD (years) & $1.04 \pm 0.64$ & $0.99 \pm 0.54$ & $0.89 \pm 0.50$ \\
Median (min, max) & $0.92(0.0,6.1)$ & $0.93(0.0,4.0)$ & $0.77(0.0,3.7)$ \\
\hline
\end{tabular}

Data includes duration of secukinumab taken in clinical studies

$n^{\text {a }}$ number of patients with evaluation (i.e. with non-missing data), $N$ number of patients in the study population, $S D$ standard deviation

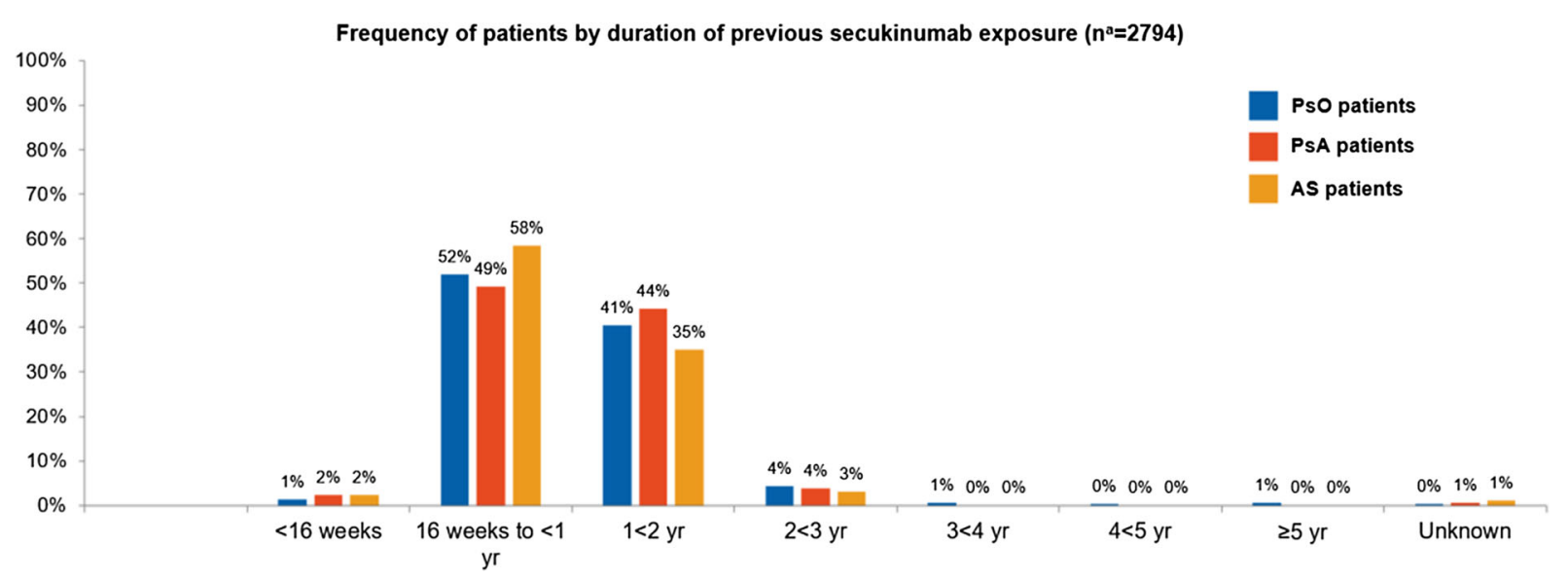

Fig. 2 Duration of secukinumab treatment prior to inclusion into SERENA study $\left(n^{\mathrm{a}}=2794\right)$. $n^{\mathrm{a}}$ number of patients with evaluation (i.e. with non-missing data); data includes also duration of secukinumab taken in clinical studies

\section{Treatment Prior to Study Enrolment}

Patients were treated with secukinumab for a mean duration of 1 year prior to enrolment (range 0.89-1.04 years, Table 2) and maximum duration of 3.7-6.1 years across indications, with a majority of patients treated for a period between 16 weeks and 2 years (Fig. 2). Prior to treatment with secukinumab, the proportions of patients with PsO, PsA and AS who had received biologic therapy for the respective indications were $31.5 \%, 59.7 \%$ and $55 \%$, respectively (Fig. 3). Among patients with $\mathrm{PsO}$, the most frequently used biologic drug for the treatment of PsO was adalimumab (58.6\%), followed by ustekinumab $(44.3 \%)$, etanercept (42.2\%) and infliximab (21.3\%, Supplementary Fig. 2a). Among patients with PsA and patients with AS, the most frequently used biologic was adalimumab (56\% and 51\%), followed by etanercept $(45.8 \%$ and $46.6 \%)$, golimumab $(32.5 \%$ and $31.6 \%)$ and infliximab $(30.3 \%$ and 28.9\%, Supplementary Fig. 2b, c).

Among the 586 patients with $\mathrm{PsO}$ treated with biologics for either PsO or PsA prior to secukinumab, half $(49.4 \%)$ of the patients were treated with one biologic drug only (Fig. 4). A quarter of the patients were treated with either two $(25.0 \%)$ or three and more biologics (25.8\%). Similar results were observed in patients with AS. Previous treatment with one biologic drug among patients with PsA was less frequent $(39.8 \%)$ compared to patients with $\mathrm{PsO}$ and patients with AS. Compared to patients with AS and patients with PsO, more patients with PsA (34.7\%) received secukinumab after previous treatment with at least three biologics drugs. Previous biologic treatment had been discontinued for the majority of patients (range $81.7-90.6 \%$ across indications) as a result of lack 


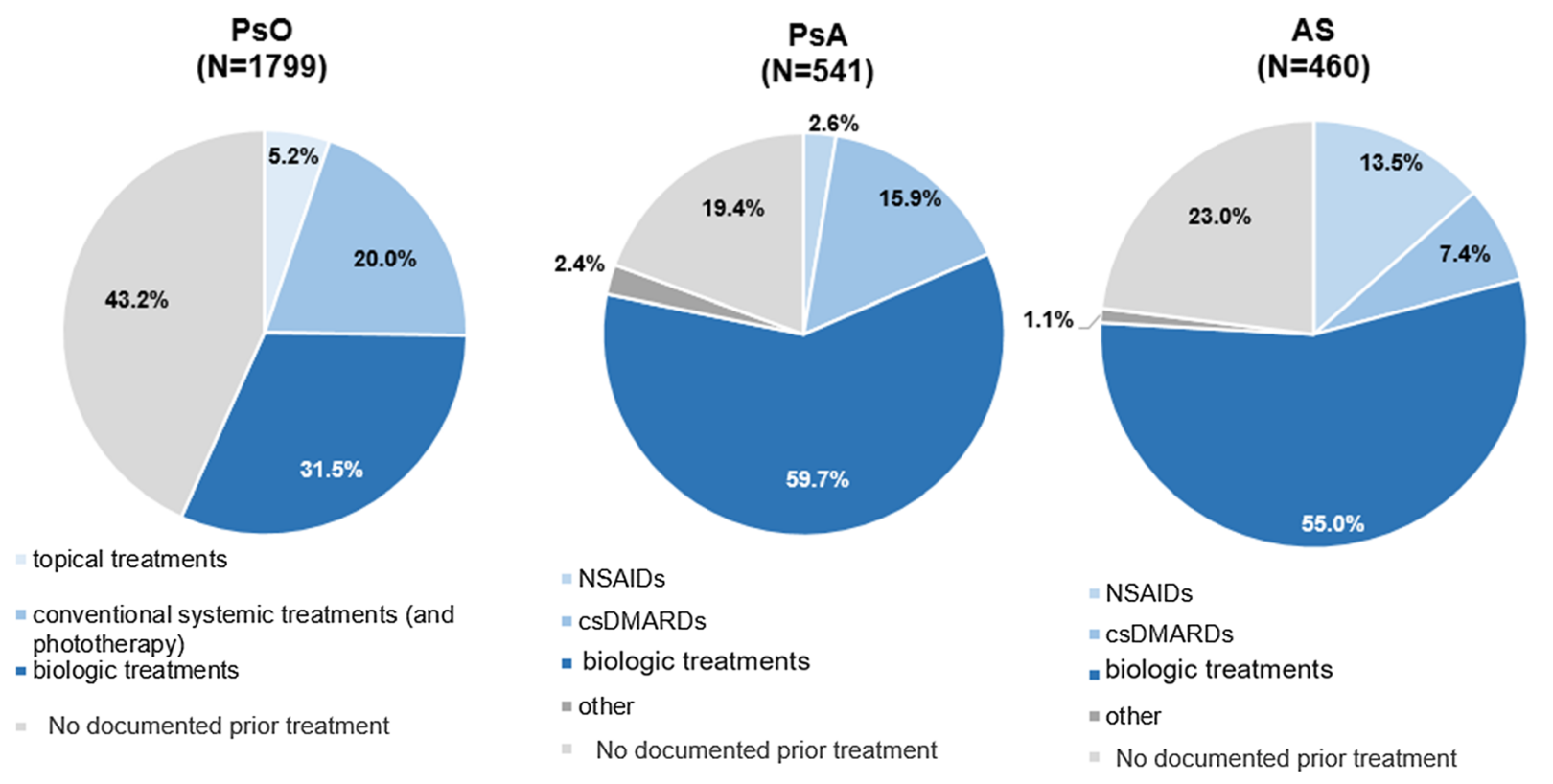

Fig. 3 Psoriasis treatment taken prior to start of secukinumab treatment. Patients treated with conventional systemic therapy could also have received topical treatment/NSAIDs; patient treated with biologics could also have received topical/NSAIDs and/or conventional treatment. NSAIDs non-steroidal anti-inflammatory drugs, csDMARDs conventional systemic disease-modifying antirheumatic drugs

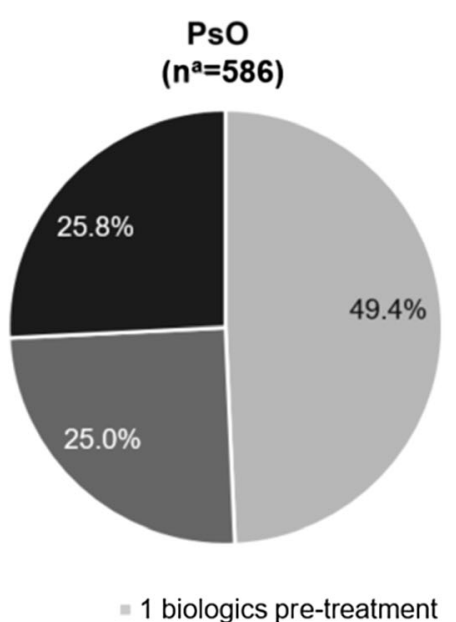

Fig. 4 Frequency of biologic pre-treated patients by number of previous therapies. $n^{\mathrm{a}}$ number of patients with evaluation of efficacy (Fig. 5). Prior to inclusion into the study, most patients received secukinumab alone (75\% in PsO, $48.2 \%$ in PsA and $48.9 \%$ in AS groups). In total, $19.3 \%$ of patients with $\mathrm{PsO}$ were treated with topical treatments in addition to secukinumab, and a small proportion received additionally conventional systemic treatments or phototherapy. Among patients with PsA, $34.4 \%$ of patients received csDMARDs in addition to secukinumab; $9.4 \%$ were treated with NSAIDs. In total, $17.2 \%$ of patients with AS were treated with csDMARDs and $27.8 \%$ received NSAIDs as the only additional therapy (Fig. 6). About one-fifth of the patients with PsO and PsA had a family history of PsO mostly involving first-degree relatives (FDRs, 19.1\% 


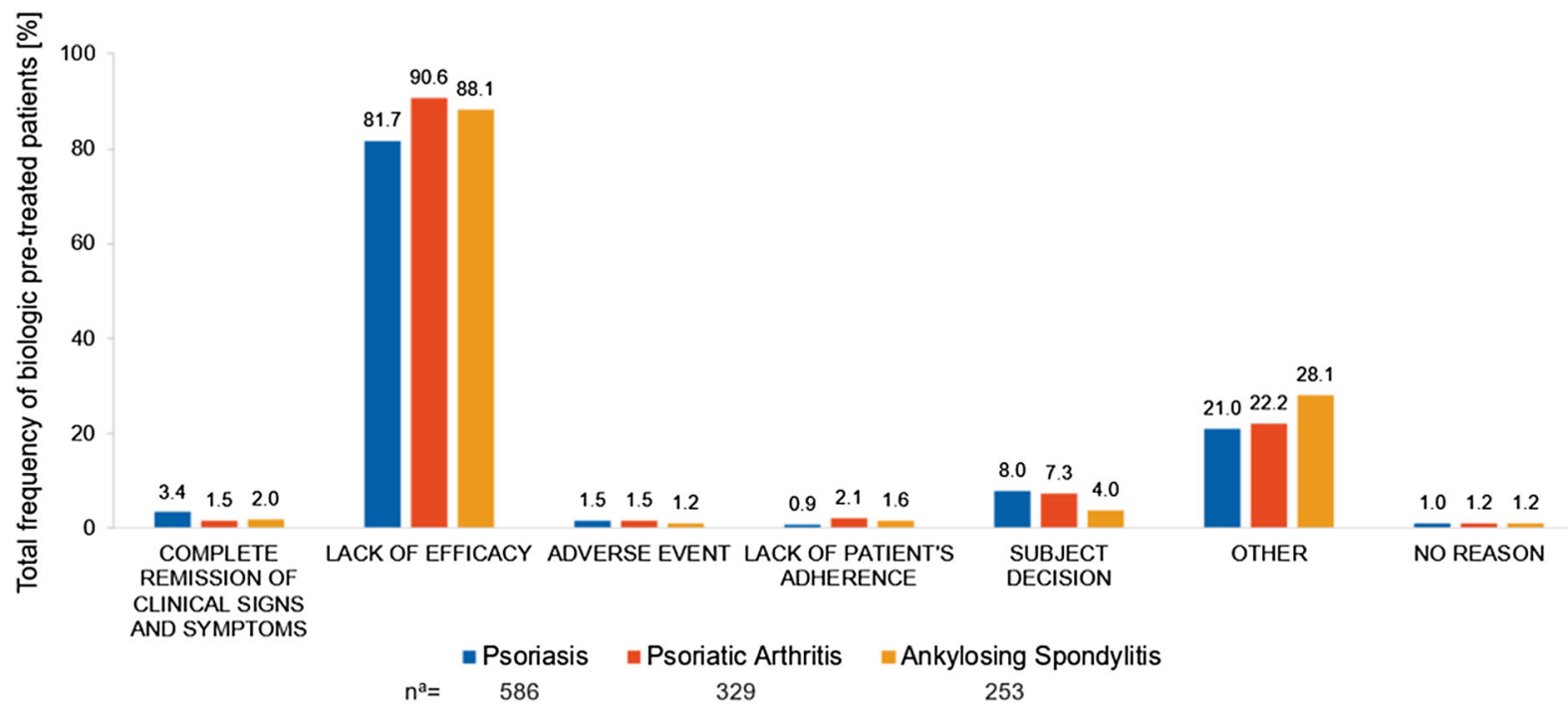

Fig. 5 Frequency of patients by reason for discontinuation of previous biologic treatment. $n^{\text {a }}$ number of patients with evaluation (i.e. biologic pre-treated); Patients could be

treated with more than one biologic drug prior to secukinumab and may be counted in more than one group

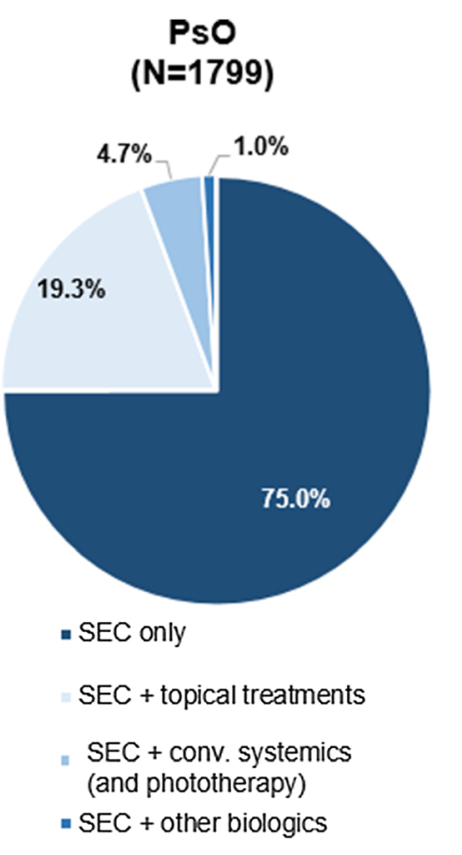

Fig. 6 Psoriasis and AS treatment taken concomitantly to secukinumab treatment. Patients treated with conventional systemic therapy could also have received topical/NSAID treatment, patient treated with biologics could also have

and 17.6\%, respectively). Similarly, about 17-20\% of the patients with PsA and AS had a family history of arthritis, mostly involving
PsA
$(\mathrm{N}=541)$

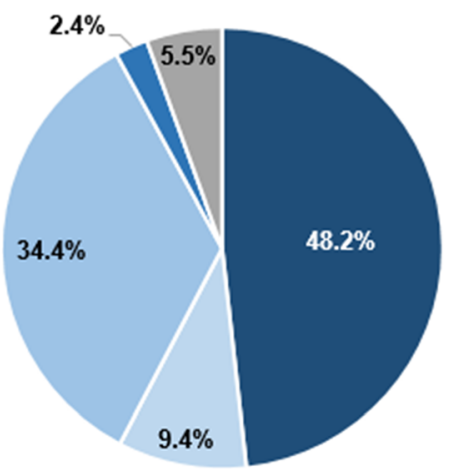

- SEC only

$=$ SEC + NSAIDS

= SEC + CSDMARDS

- SEC + other biologics

- SEC + other
AS

$(\mathrm{N}=460)$

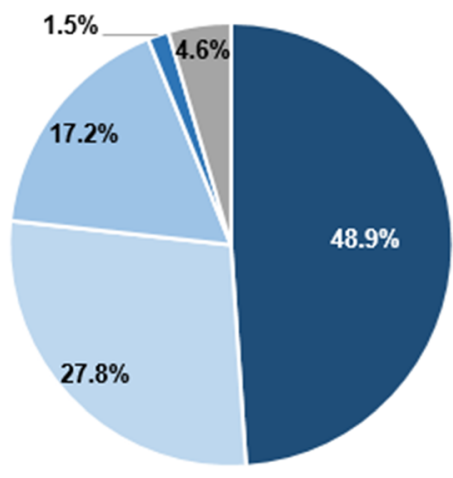

- SEC only

$=$ SEC + NSAIDs

= SEC + cSDMARDS

- SEC + other biologics

- SEC + other received topical /NSAID and/or conventional treatment. Conv conventional, SEC secukinumab, NSAIDs nonsteroidal anti-inflammatory drugs, csDMARDs conventional systemic disease-modifying antirheumatic drugs

FDRs (Fig. 7). Family history of other inflammatory diseases was less common with a frequency of $10.9 \%$ in patients with AS. 

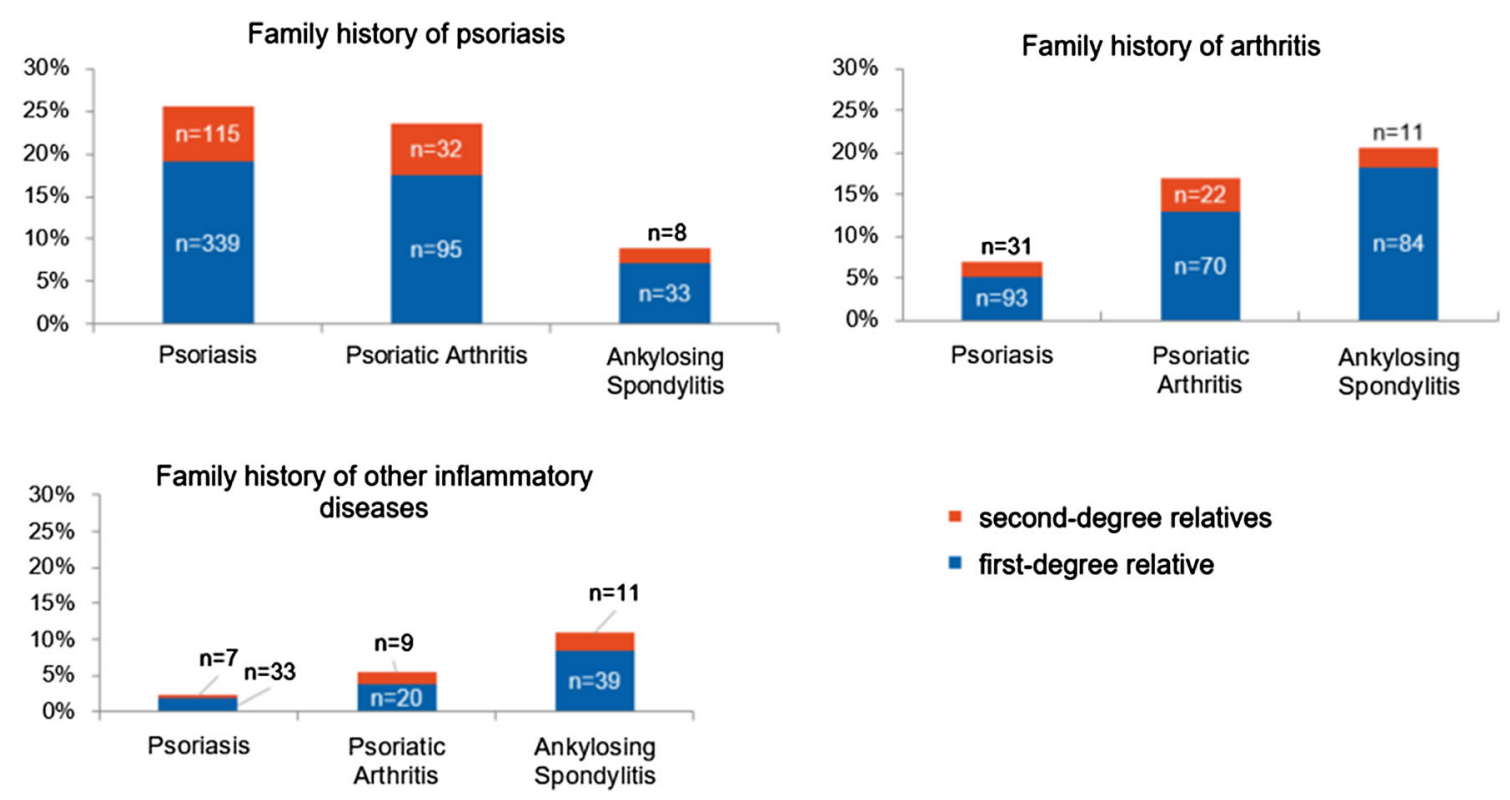

- second-degree relatives

- first-degree relative

Fig. 7 Familial history of inflammatory diseases. A firstdegree relative is defined as a close blood relative which includes the individual's parents, full siblings or children. A

second-degree relative is defined as a blood relative which includes the individual's grandparents, grandchildren, aunts, uncles, nephews, nieces or half-siblings

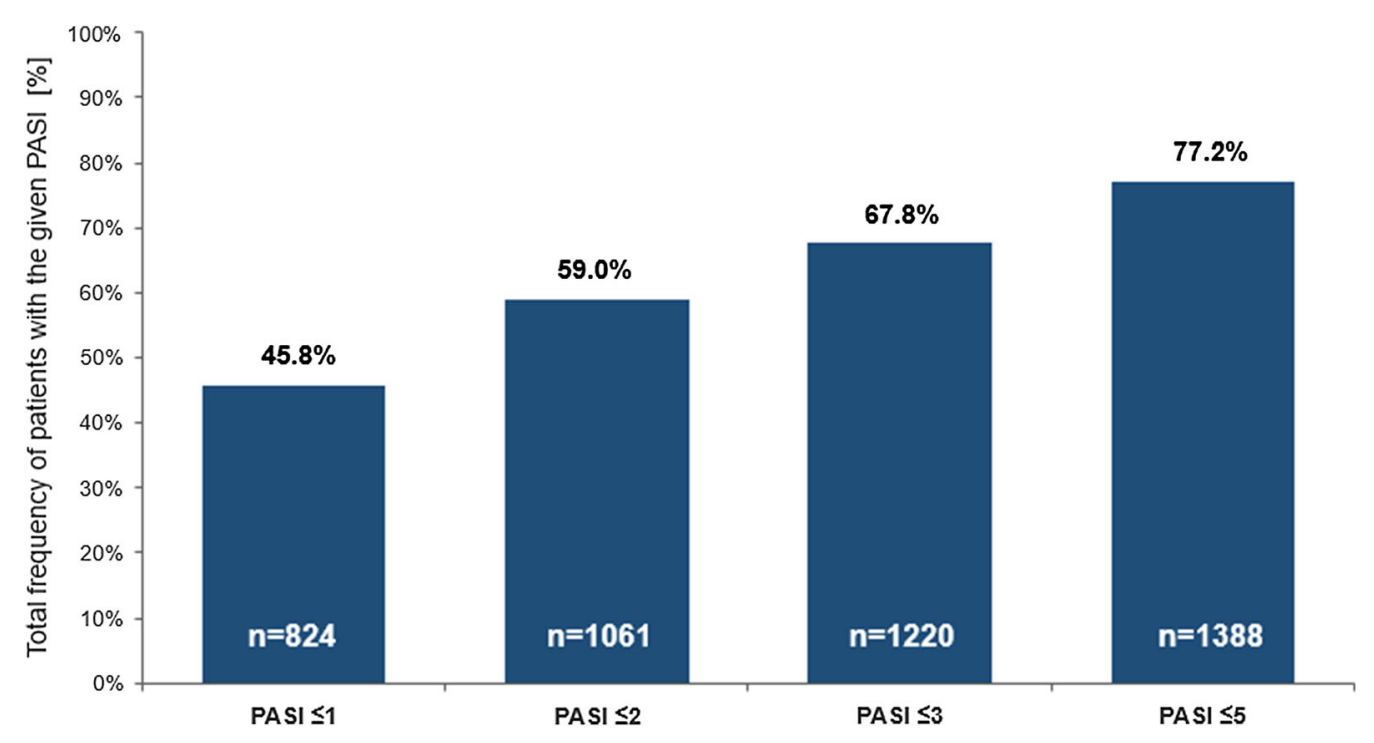

Fig. 8 Percentage of patients by absolute PASI score category at enrolment. PASI Psoriasis Area and Severity Index

\section{Disease Activity Status (at Start of Therapy and at Study Enrolment)}

The mean PASI score at the treatment start of secukinumab was $20.7 \pm 12.8(n=1605)$ and $7.6 \pm 10.2(n=128)$ in PsO and PsA groups, respectively. However, when the patients were enrolled in SERENA, the mean PASI score was $3.0 \pm 6.7(n=1648)$ and $2.0 \pm 7.2(n=221)$, respectively. Absolute PASI scores were low at enrolment (at mean 1 year after therapy start) with $45.8 \%$ of patients having PASI $\leq 1$ (Fig. 8). Disease activity was measured at enrolment into the study and is presented in Table 3. In total, 
Table 3 Disease activity status at enrolment

\begin{tabular}{llll}
\hline Characteristic & PsO $(\boldsymbol{N}=\mathbf{1 7 9 9})$ & PsA $(\boldsymbol{N}=\mathbf{5 4 1})$ & AS $(\boldsymbol{N}=\mathbf{4 6 0})$ \\
\hline PGA response 0/1 (clear/almost clear skin), $n / M(\%)$ & $531 / 740(71.8 \%)$ & $192 / 314(61.1 \%)$ & - \\
Tender joint count, mean \pm SD $(M)$ & - & $6.4 \pm 9.5(211)$ & - \\
Swollen joint count, mean \pm SD $(M)$ & - & $3.3 \pm 5.8(212)$ & - \\
Absence of tender or swollen joint, $n / M(\%)$ & - & $236 / 521(45.3 \%)$ & - \\
HAQ-DI Score, mean \pm SD $(M)$ & $0.50 \pm 0.57(26)$ & $0.83 \pm 0.71(404)$ & $0.81 \pm 0.70(430)$ \\
ASDAS-CRP, mean \pm SD $(M)$ & - & - & $2.3 \pm 0.9(234)$ \\
Enthesitis index, mean \pm SD $(M)$ & - & $0.4 \pm 1.1^{\mathrm{a}}(275)$ & $0.7 \pm 1.7^{\mathrm{b}}(243)$ \\
Pain (VAS 0-100 mm), mean \pm SD $(M)$ & - & $31.9 \pm 24.2^{\mathrm{c}}(440)$ & $34.9 \pm 24.2^{\mathrm{d}}(349)$ \\
BASDAI, mean \pm SD $(M)$ & - & - & $3.3 \pm 2.3(423)$ \\
PtGA of AS (VAS 0-10 cm), mean \pm SD $(M)$ & - & - & $4.2 \pm 2.3(360)$ \\
CRP (mg/L), mean \pm SD $(M)$ & - & - & $8.8 \pm 14.1(287)$ \\
\hline
\end{tabular}

$A S$ ankylosing spondylitis, ASDAS Ankylosing Spondylitis Disease Activity Score, BASDAI Bath Ankylosing Spondylitis Disease Activity Index, $C R P$ C-reactive protein, $M$ number of patients with evaluation, $n$ number of patients with a response, $N$ number of patients in the study population, $P G A$ Physician's Global Assessment, $P s A$ psoriatic arthritis, $P s O$ psoriasis, PtGA Patient's Global Assessment, $S D$ standard deviation, $V A S$ visual analogue scale

a Leeds enthesitis index

b Maastricht Ankylosing Spondylitis Enthesitis Score

c Total pain

$\mathrm{d}$ Total back pain

$71.8 \%$ of patients with $\mathrm{PsO}$ and $61.1 \%$ of patients with PsA reported PGA 0/1 (clear or almost clear skin) at enrolment. Among patients with PsA, 54.7\% presented with joint involvement (any joint tender or swollen) with a mean (SD) number of tender 6.4 (9.5) and swollen joints 3.3 (5.8). About one-fifth (19\%) of the patients with PsA had enthesitis (LEI, mean (SD) 0.4 [1.1]) at enrolment. Overall, $21.6 \%$ of patients with PsO without PsA at enrolment, $32.4 \%$ of patients with PsO and PsA at enrolment and $17.8 \%$ of patients with PsA had nail involvement, respectively. Overall, $0.6 \%$ of patients with $\mathrm{PsO}$ without formally diagnosed PsA at enrolment, 6.9\% of patients with $\mathrm{PsO}$ and PsA at enrolment and $6.6 \%$ of patients with PsA had dactylitis, respectively.

Patients with AS at enrolment had mean (SD) ASDAS-CRP score of 2.3 (0.9) and BASDAI score of 3.3 (2.3). A proportion of patients with AS had achieved ASDAS-CRP inactive disease status
(15.4\%) or low disease activity (31.6\%) at the time of enrolment (Supplementary Fig. 3). In total, $26 \%$ of patients with AS had enthesitis (MASES) with a mean (SD) enthesitis index of 0.7 (1.7). The mean (SD) Patient's Global Assessment of AS (VAS $10 \mathrm{~cm}$ ) and total back pain (VAS $100 \mathrm{~mm}$ ) scores were 4.2 (3.2) and 34.9 (24.2), respectively. In the overall AS population, mean (SD) CRP was 8.8 (14.1) $\mathrm{mg} / \mathrm{L}$ at enrolment; more than a half of patients with AS $(58.5 \%)$ had normal CRP $(\leq 5 \mathrm{mg} / \mathrm{mL})$ levels (overall median of $4 \mathrm{mg} / \mathrm{L}$ ).

\section{Safety}

The cumulative exposure to secukinumab treatment prior to enrolment was 2809.8 patient-years. There were low rates of retrospective reporting of events of special interest. The percentage of patients reporting any infection was 
Table 4 Medical history: patients reporting events of special interest occurring prior to enrolment during the secukinumab treatment

\begin{tabular}{lllll}
\hline & PsO $(\boldsymbol{N}=\mathbf{1 7 9 9})$ & PsA $(\boldsymbol{N = 5 4 1})$ & AS $(\boldsymbol{N}=\mathbf{4 6 0})$ & Total $(\boldsymbol{N}=\mathbf{2 8 0 0})$ \\
\hline Total exposure (patient-years) & 1870.9 & 533.1 & 405.8 & 2809.8 \\
Candida infections, $n$ (\%) & $12(0.7)$ & - & - & $12(0.43)$ \\
Malignancy, $n$ (\%) & $9(0.5)$ & $2(0.4)$ & $1(0.2)$ & $12(0.43)$ \\
Major adverse cardiovascular events, $n(\%)$ & $1(0.1)$ & - & - & $1(0.04)$ \\
Inflammatory bowel disease, $n$ (\%) & - & $1(0.2)$ & $1(0.2)$ & $2(0.07)$ \\
Injection site reactions, $n(\%)$ & $1(0.1)$ & - & - & $1(0.04)$ \\
Infections ${ }^{\mathrm{a}}, n(\%)$ & $72(4.0)$ & $10(1.8)$ & $11(2.4)$ & $93(3.3)$ \\
\hline
\end{tabular}

Only events occurred during the exposure to secukinumab are reported

$n$ number of patients with an event, $\%$ percentage of patients with an event

a Including Candida infections

$3.3 \%$. Higher rates of patients reporting any infection were observed among patients with PsO (4.0\%) than among patients with PsA $(1.8 \%)$ or patients with AS $(2.4 \%)$. Overall, two cases $(0.07 \%)$ of IBD were reported (one each in PsA and AS cohort), both of which were newonset. No unexpected safety signals were reported (Table 4).

\section{DISCUSSION}

SERENA is the first study to investigate secukinumab use in everyday clinical practice in Europe across all three therapeutic indications: moderate to severe plaque PsO, active PsA and active AS. In addition, SERENA includes patients with potential comorbidities, prior or concomitant medications that may have led to their exclusion from randomized controlled trials (RCTs). Furthermore, non-interventional studies provide complementary evidence to RCTs, comparative effectiveness with other treatments that can inform payers and clinicians and may result in hypothesis generation $[50,56]$. Finally, SERENA will collect long-term retention (primary endpoint) and safety outcomes in broad populations treated in routine clinical practice.

The demographics in SERENA are consistent with other interventional trials with secukinumab in PsO, PsA and AS $[43,54,55,57,58]$, and other real-world studies $[59,60]$.

However, in terms of baseline disease characteristics, the time since diagnosis of AS was longer in SERENA with a mean duration of 9.3 years as opposed to RCTs ranging from 5.3 to 8.3 years. Furthermore, disease activity at enrolment was generally less severe than those reported at baseline in phase 3 clinical trials because the majority of the patients included in the SERENA study received secukinumab treatment for a period between 16 weeks and 2 years with a mean duration of 1 year (range 0.89-1.04 years) prior to enrolment [46-48, 75-79].

In contrast to phase 3 secukinumab trials [46-48], most patients enrolled in SERENA were treated with other biologics (mostly anti-TNFs) prior to receiving secukinumab. Notably, more than one-quarter of these patients received three or more biologics prior to secukinumab. Among all three cohorts, lack of efficacy was the major reason for discontinuation and hence effectiveness data should be interpreted by taking into consideration that previous treatments had not adequately controlled disease symptoms. These results are similar to findings from two large non-interventional studies in Germany, AQUILA (secukinumab use in patients with active AS or PsA) [60] and PROSPECT 
(secukinumab use in patients with active moderate to severe PsO) [61]. The US Psoriasis Registry CORRONA also reports comparable conclusions [80-82].

Safety data presented here are related to events that occurred during the exposure to secukinumab preceding the enrolment to the study. As a result of the retrospective character of safety data collection, some of the safety events, especially those of mild nature, might not be reported. Nevertheless, no new safety signals were identified within the analysis of available data. Further analyses of safety events observed during the study will provide further valuable information into safety aspects of secukinumab use in the real world.

The limitations of this study result from its observational nature including absence of control group, incomplete data and selection bias. For example, some baseline characteristics such as the use of prior medications other than biologics were not collected if exposure occurred more than 6 months prior to enrolment. Selection bias was inevitably introduced as patients had to be treated for at least 16 weeks with secukinumab prior to enrolment as the main objective of this study is to focus on the longterm drug retention and safety rather than initial effectiveness of secukinumab treatment. Efficacy achieved within 16 weeks of treatment is already well proven in the clinical development program of secukinumab. Furthermore, SERENA was conducted in 19 countries in Europe only, and findings cannot be generalized to all patients with PsO, PsA and AS worldwide. In addition, there was an imbalance between the number of patients enrolled in countries. Since the data have been collected retrospectively for up to 6 years for some individuals, underreporting of prior medications and more importantly of adverse events cannot be excluded. All limitations have descriptive character only, with no adjustments made to control for potential confounding variables.

\section{CONCLUSIONS}

In terms of demographics, the SERENA population is consistent with other interventional trials with secukinumab; however, there are some significant differences pertinent to the baseline disease characteristics. Patients enrolled in SERENA had prior exposure to multiple biologics, mostly TNF inhibitors, and relatively lower disease activity compared to phase 3 studies as they were already treated with secukinumab for a period between 16 weeks and 2 years.

This large observational study across all three secukinumab indications will provide further information on the long-term effectiveness and safety of secukinumab in the real-world setting. Full effectiveness and safety results will be reported in a future publication.

\section{ACKNOWLEDGEMENTS}

The authors thank all patients and investigators who participated in this study.

Funding. This study, the journal's Rapid Service and Open Access Fees were funded by Novartis Pharma AG.

Medical Writing Assistance. The authors also thank Sumeet Sood, PhD (Novartis Healthcare Pvt. Ltd, Hyderabad) for editorial and medical writing support, which was funded by Novartis Pharma AG, in accordance with the Good Publication Practice (GPP3) guidelines (https://www.ismpp.org/gpp3).

Authorship. All named authors meet the International Committee of Medical Journal Editors (ICMJE) criteria for authorship for this article, take responsibility for the integrity of the work as a whole, and have given their approval for this version to be published.

Disclosures. Uta Kiltz has received grant and research support and consultancy fees from AbbVie, Amgen, Biocad, Biogen, Chugai, Eli Lilly, Grünenthal, Janssen, MSD, Novartis, Pfizer, Roche and UCB. Petros P. Sfikakis has been principal investigator in clinical trials sponsored by and/or has received personal fees for scientific contributions from AbbVie, Amgen, 
Boehringer Inglheim, Celgene, Eli-Lilly, Janssen, Novartis and Pfizer. Karl Gaffney has received research grants, educational grants and consultancy fees from AbbVie, Celgene, EliLilly, Gilead, MSD, Pfizer, Novartis and UCB. Paul-Gunther Sator has been an advisor and/or received speaker honoraria or travel expense reimbursements and/or received grants and/or participated in clinical trials for AbbVie, Actelion, Amgen, Almirall, Janssen, Novartis, Leo Pharma, Pfizer, MSD, Celgene, Maruho, ALK, Galderma Abbott, UCB, Gilead, and Eli Lilly. Ralph von Kiedrowski declares that, through his own company CMS GmbH, he has received honoraria for lectures, consultancy work, and studies from AbbVie, Almirall, Biofrontera, Biogen, Celgene, Dr. Pfleger, Foamix, JanssenCilag, Leo, Eli Lilly, Medac, MSD, Novartis, Pfizer, Tigercat, and UCB. Nicola Gullick received conference support and/or research funds and/ or speaker fees and/or consulting fees from Celgene, Eli Lilly, Janssen, UCB, Izana, Novartis and AbbVie. Curdin Conrad served as scientific adviser and/or clinical study investigator and/or paid speaker for AbbVie, Actelion, Amgen, BMS, Celgene, Galderma, Incyte, Janssen, LEO Pharma, Lilly, MSD, Novartis, Pfizer, and UCB. Dimitris Rigopoulos has received consultancy fees, payment for lectures and support for travel to scientific meetings from Celgene, Novartis, Janssen and Abbvie. Eric Lespessailles received speaker and consultant fees from Amgen, Expanscience, Lilly and MSD, and research grants from Abbvie, Amgen, Lilly, MSD and UCB. Marco Romanelli has participated in the advisory board of AbbVie, Eli Lilly, Novartis and Urgo. Pierre-Dominique Ghislain has received speaker fees, participated in clinical trials and/or advisory boards for Wyeth/Pfizer, ScheringPlough/MSD, Abbott, AbbVie, Janssen-Cilag, Merck-Serono, Leo, Novartis, UCB, Amgen, Celgene, Eli-Lilly, Galderma, BMS, Meda, Maruho, Flen, Menarini, Almirall, PellePharm and Mylan. Matthias Augustin has served as a consultant or paid speaker for clinical trials sponsored by companies that manufacture drugs used for the treatment of psoriasis, including AbbVie, Almirall, Amgen, Biogen, Boehringer Ingelheim, Celgene, Centocor, Eli Lilly, GSK, Janssen-Cilag, Leo, Medac, Merck, MSD,
Novartis, Pfizer, UCB, and XenoPort. Jan Brandt-Jürgens, Andreas Bounas and Rasho Rashkov have nothing to disclose. Roberto Orsenigo, Chiara Perella, Maher Aassi, Piotr Jagiello, Effie Pournara, Sven Gathmann and Justyna Veit are employed by Novartis.

Compliance with Ethics Guidelines. All patients provided written informed consent before enrolling into the study. The study protocol was approved by the institutional review board of each participating centre (Supplementary Material). The trial was conducted in accordance with the Declaration of Helsinki and Good Clinical Practice (GCP) and in compliance with all federal, local or regional requirements.

Data Availability. The datasets generated during and/or analysed during the current study are not publicly available. Novartis is committed to sharing with qualified external researchers access to patient-level data and supporting clinical documents from eligible studies. These requests are reviewed and approved on the basis of scientific merit. All data provided is anonymized to respect the privacy of patients who have participated in the trial in line with applicable laws and regulations. The data may be requested from the corresponding author of the manuscript.

Open Access. This article is licensed under a Creative Commons Attribution-NonCommercial 4.0 International License, which permits any non-commercial use, sharing, adaptation, distribution and reproduction in any medium or format, as long as you give appropriate credit to the original author(s) and the source, provide a link to the Creative Commons licence, and indicate if changes were made. The images or other third party material in this article are included in the article's Creative Commons licence, unless indicated otherwise in a credit line to the material. If material is not included in the article's Creative Commons licence and your intended use is not permitted by statutory regulation or exceeds the permitted use, you will need to obtain permission directly from the copyright holder. To view a copy of this licence, 
visit http://creativecommons.org/licenses/bync/4.0/.

\section{REFERENCES}

1. Schreiber S, Colombel J-F, Feagan BG, et al. Incidence rates of inflammatory bowel disease in patients with psoriasis, psoriatic arthritis and ankylosing spondylitis treated with secukinumab: a retrospective analysis of pooled data from 21 clinical trials. Ann Rheum Dis. 2019;78(4):473-9.

2. Ayala-Fontánez N, Soler DC, McCormick TS. Current knowledge on psoriasis and autoimmune diseases. Psoriasis (Auckl). 2016;6:7-32.

3. Turkiewicz AM, Moreland LW. Psoriatic arthritis: current concepts on pathogenesis-oriented therapeutic options. Arthritis Rheum. 2007;56(4): 1051-66.

4. Zeng J, Luo S, Huang Y, Lu Q. Critical role of environmental factors in the pathogenesis of psoriasis. J Dermatol. 2017;44(8):863-72.

5. Avaloz-Diaz E, Dominguez-Cherit J, Herrera-Esparza R. Cutaneous manifestations of spondyloarthritis. Int J Clin Rheumatol. 2012;7(1):55-61.

6. Puig L, Thom H, Mollon P, Tian H, Ramakrishna GS. Clear or almost clear skin improves the quality of life in patients with moderate-to-severe psoriasis: a systematic review and meta-analysis. J Eur Acad Dermatol Venereol. 2017;31(2):213-20.

7. Mattei PL, Corey KC, Kimball AB. Psoriasis Area Severity Index (PASI) and the Dermatology Life Quality Index (DLQI): the correlation between disease severity and psychological burden in patients treated with biological therapies. J Eur Acad Dermatol Venereol. 2014;28(3):333-7.

8. Wervers K, Luime JJ, Tchetverikov I, et al. Influence of disease manifestations on health-related quality of life in early psoriatic arthritis. J Rheumatol. 2018;45(11):1526-31.

9. Kotsis K, Voulgari PV, Drosos AA, Carvalho AF, Hyphantis T. Health-related quality of life in patients with ankylosing spondylitis: a comprehensive review. Expert Rev Pharmacoecon Outcomes Res. 2014;14(6):857-72.

10. Boehncke WH, Schon MP. Psoriasis. Lancet. 2015;386(9997):983-94.

11. Augustin M, Reich K, Glaeske G, Schaefer I, Radtke M. Co-morbidity and age-related prevalence of psoriasis: analysis of health insurance data in Germany. Acta Dermato-venereol. 2010;90(2):147-51.

12. von Stebut E, Reich K, Thaci D, et al. Impact of secukinumab on endothelial dysfunction and other cardiovascular disease parameters in psoriasis patients over 52 weeks. J Invest Dermatol. 2019;139(5):1054-62.

13. Cohen AD, Dreiher J, Birkenfeld S. Psoriasis associated with ulcerative colitis and Crohn's disease. J Eur Acad Dermatol Venereol. 2009;23(5):561-5.

14. Husni ME. Comorbidities in psoriatic arthritis. Rheum Dis Clin N Am. 2015;41(4):677-98.

15. Molto A, Dougados M. Comorbidities in spondyloarthritis including psoriatic arthritis. Best Pract Res Clin Rheumatol. 2018;32(3):390-400.

16. Lebwohl M. Psoriasis. Lancet. 2003;361(9364): 1197-204.

17. Pettey AA, Balkrishnan R, Rapp SR, Fleischer AB, Feldman SR. Patients with palmoplantar psoriasis have more physical disability and discomfort than patients with other forms of psoriasis: implications for clinical practice. J Am Acad Dermatol. 2003;49(2):271-5.

18. Radtke MA, Langenbruch AK, Schafer I, Herberger K, Reich K, Augustin M. Nail psoriasis as a severity indicator: results from the PsoReal study. Patient Relat Outcome Meas. 2011;2:1-6.

19. Menter A. Psoriasis and psoriatic arthritis overview. Am J Managed Care. 2016;22(8 Suppl): s216-s224224.

20. Beck KM, Yang EJ, Sanchez IM, Liao W. Treatment of genital psoriasis: a systematic review. Dermatol Ther (Heidelb). 2018;8(4):509-25.

21. Parisi R, Symmons DP, Griffiths CE, Ashcroft DM. Global epidemiology of psoriasis: a systematic review of incidence and prevalence. J Invest Dermatol. 2013;133(2):377-85.

22. Alinaghi F, Calov M, Kristensen LE, et al. Prevalence of psoriatic arthritis in patients with psoriasis: a systematic review and meta-analysis of observational and clinical studies. J Am Acad Dermatol. 2019;80(1):251-65.e19.

23. Haroon M, Kirby B, FitzGerald O. High prevalence of psoriatic arthritis in patients with severe psoriasis with suboptimal performance of screening questionnaires. Ann Rheum Dis. 2013;72(5):736-40.

24. European Medicines Agency. Guideline on clinical investigation of medicinal products indicated for the treatment of psoriasis. EMA. 2004. https://www. 
ema.europa.eu/en/documents/scientific-guideline/ guideline-clinical-investigation-medicinal-productsindicated-treatment-psoriasis_en.pdf. Accessed 12 Feb 2020.

25. Ryan C, Korman NJ, Gelfand JM, et al. Research gaps in psoriasis: opportunities for future studies. J Am Acad Dermatol. 2014;70(1):146-67.

26. Chiricozzi A, Balato A, Conrad C, et al. Secukinumab demonstrates improvements in absolute and relative psoriasis area severity indices in moderate-to-severe plaque psoriasis: results from a European, multicentric, retrospective, real-world study. J Dermatol Treat. 2019:1-8. https://doi.org/ 10.1080/09546634.2019.1671577.

27. Sieper J, Rudwaleit M, Baraliakos X, et al. The Assessment of Spondyloarthritis International Society (ASAS) handbook: a guide to assess spondyloarthritis. Ann Rheumatic Dis. 2009;68(Suppl 2):ii1-44.

28. Garg N, van den Bosch F, Deodhar A. The concept of spondyloarthritis: where are we now? Best Pract Res Clin Rheumatol. 2014;28(5):663-72.

29. Taylor W, Gladman D, Helliwell P, et al. Classification criteria for psoriatic arthritis: development of new criteria from a large international study. Arthritis Rheum. 2006;54(8):2665-733.

30. Belasco J, Wei N. Psoriatic arthritis: what is happening at the joint? Rheumatol Ther. 2019;6(3): 305-15.

31. Olivieri I, D'Angelo S, Palazzi C, Padula A. Advances in the management of psoriatic arthritis. Nat Rev Rheumatol. 2014;10(9):531-42.

32. Gao X, Wendling D, Botteman MF, Carter JA, Rao S, Cifaldi M. Clinical and economic burden of extraarticular manifestations in ankylosing spondylitis patients treated with anti-tumor necrosis factor agents. J Med Econ. 2012;15(6):1054-63.

33. Stolwijk C, van Tubergen A, Castillo-Ortiz JD, Boonen A. Prevalence of extra-articular manifestations in patients with ankylosing spondylitis: a systematic review and meta-analysis. Ann Rheum Dis. $2015 ; 74(1): 65-73$.

34. Mielants H, Van den Bosch F. Extra-articular manifestations. Clin Exp Rheumatol. 2009;27(4 Suppl 55):S56-61.

35. Elewaut D, Matucci-Cerinic M. Treatment of ankylosing spondylitis and extra-articular manifestations in everyday rheumatology practice. Rheumatology (Oxford). 2009;48(9):1029-35.
36. Dean LE, Jones GT, MacDonald AG, Downham C, Sturrock RD, Macfarlane GJ. Global prevalence of ankylosing spondylitis. Rheumatology (Oxford). 2014;53(4):650-7.

37. Ivanov S, Linden A. Interleukin-17 as a drug target in human disease. Trends Pharmacol Sci. 2009;30(2):95-103.

38. Miossec P, Kolls JK. Targeting IL-17 and TH17 cells in chronic inflammation. Nat Rev Drug Discovery. 2012;11(10):763-76.

39. Lynde CW, Poulin Y, Vender R, Bourcier M, Khalil S. Interleukin 17A: toward a new understanding of psoriasis pathogenesis. J Am Acad Dermatol. 2014;71(1):141-50.

40. Keijsers RR, Joosten I, van Erp PE, Koenen HJ, van de Kerkhof PC. Cellular sources of IL-17 in psoriasis: a paradigm shift? Exp Dermatol. 2014;23(11): 799-803.

41. Nestle FO, Kaplan DH, Barker J. Psoriasis. N Engl J Med. 2009;361(5):496-509.

42. Braun T, Zwerina J. Positive regulators of osteoclastogenesis and bone resorption in rheumatoid arthritis. Arthritis Res Ther. 2011;13(4):235.

43. Maruotti N, Grano M, Colucci S, d'Onofrio F, Cantatore FP. Osteoclastogenesis and arthritis. Clin Exp Med. 2011;11(3):137-45.

44. Lories RJ, McInnes IB. Primed for inflammation: enthesis-resident $T$ cells. Nat Med. 2012;18(7): 1018-9.

45. Louie GH, Ward MM. Measurement and treatment of radiographic progression in ankylosing spondylitis: lessons learned from observational studies and clinical trials. Curr Opin Rheumatol. 2014;26(2):145-50.

46. Langley RG, Elewski BE, Lebwohl M, et al. Secukinumab in plaque psoriasis-results of two phase 3 trials. N Engl J Med. 2014;371(4):326-38.

47. McInnes IB, Mease PJ, Kirkham B, et al. Secukinumab, a human anti-interleukin-17A monoclonal antibody, in patients with psoriatic arthritis (FUTURE 2): a randomised, double-blind, placebocontrolled, phase 3 trial. Lancet. 2015;386(9999): 1137-46.

48. Baeten D, Baraliakos X, Braun J, et al. Anti-interleukin-17A monoclonal antibody secukinumab in treatment of ankylosing spondylitis: a randomised, double-blind, placebo-controlled trial. Lancet. 2013;382(9906):1705-13. 
49. Bissonnette R, Luger T, Thaci D, et al. Secukinumab demonstrates high sustained efficacy and a favourable safety profile in patients with moderate-tosevere psoriasis through 5 years of treatment (SCULPTURE Extension Study). J Eur Acad Dermatol Venereol. 2018;32(9):1507-14.

50. Langley RG, Sigurgeirsson B, Szepietowski JC, et al. Secukinumab maintains improvements in psoriasis through five years of treatment: a randomized extension of the phase III ERASURE and FIXTURE trials. Oral presentation at American Academy of Dermatology (AAD) Annual Meeting, Mar 1-5, 2019, Washington D.C., USA.

51. McInnes IB, Kivitz AJ, Nash P, et al. Secukinumab provides sustained improvements in the signs and symptoms of active psoriatic arthritis: long-term (4year) data from a phase 3 study. Poster presented at The American College of Rheumatology (ACR) Annual Meeting, October 19-24, 2018, Chicago, USA.

52. Marzo-Ortega H, Sieper J, Kivitz AJ, et al. Secukinumab $150 \mathrm{mg}$ provides sustained improvements in the signs and symptoms of active ankylosing spondylitis with consistent safety profile and high retention rate: 4-year results from a phase III trial. Poster presented at The American College of Rheumatology (ACR) Annual Meeting, October 19-24, 2018, Chicago, USA.

53. Blonde L, Khunti K, Harris SB, Meizinger C, Skolnik NS. Interpretation and impact of real-world clinical data for the practicing clinician. Adv Ther. 2018;35(11):1763-74.

54. Katkade VB, Sanders KN, Zou KH. Real world data: an opportunity to supplement existing evidence for the use of long-established medicines in health care decision making. J Multidiscip Healthcare. 2018;11: 295-304.

55. Kim HS, Lee S, Kim JH. Real-world evidence versus randomized controlled trial: clinical research based on electronic medical records. J Korean Med Sci. 2018;33(34):e213.

56. COSENTYX [Summary of Product Characteristics]. Camberley, UK: Novartis Europharm Limited. 2019.

57. Korber A, Thaci D, von Kiedrowski R, Bachhuber T, Melzer N, Kasparek T, et al. Secukinumab treatment of moderate to severe plaque psoriasis in routine clinical care: real-life data of prior and concomitant use of psoriasis treatments from the PROSPECT study. J Eur Acad Dermatol Venereol. 2018;32(3): 411-9.

58. Thaci D, Korber A, von Kiedrowski R, et al. Secukinumab is effective in treatment of moderate-tosevere plaque psoriasis: real-life effectiveness and safety from the PROSPECT study. J Eur Acad Dermatol Venereol. 2020;34:310-8.

59. Kiltz U, Legeler C, Maier-Peuschel M, Mann C, Tony H-P. Baseline characteristics of patients with ankylosing spondylitis and psoriatic arthritis treated with secukinumab in the real-world setting: AQUILA, a non-interventional study. Open Rheumatol J. 2019;13:53-60.

60. Papp KA, Gooderham M, Beecker J, et al. Rationale, objectives and design of PURE, a prospective registry of patients with moderate to severe chronic plaque psoriasis in Canada and Latin America. BMC Dermatol. 2019;19(1):9.

61. Mann HF, Zavada J, Senolt L, et al. Real world use of secukinumab for treatment of axial spondyloarthritis and psoriatic arthritis: nationwide results from the ATTRA registry. Clin Exp Rheumatol. 2019;37(2):342-3.

62. Strober BE, Germino R, Guana A, et al. US realworld effectiveness of secukinumab for the treatment of psoriasis: 6-month analysis from the Corrona Psoriasis Registry. J Dermatol Treat. 2019;1-9. https://doi.org/10.1080/09546634.2019.1603361

63. Blauvelt A, Reich K, Tsai T-F, et al. Secukinumab is superior to ustekinumab in clearing skin of subjects with moderate-to-severe plaque psoriasis up to 1 year: results from the CLEAR study. J Am Acad Dermatol. 2017;76(1):60-9.e9.

64. Mease P, van der Heijde D, Landewe $R$, et al. Secukinumab improves active psoriatic arthritis symptoms and inhibits radiographic progression: primary results from the randomised, double-blind, phase III FUTURE 5 study. Ann Rheum Dis. 2018;77(6):890-7.

65. Weisman S, Pollack CR, Gottschalk RW. Psoriasis disease severity measures: comparing efficacy of treatments for severe psoriasis. J Dermatol Treat. 2003;14(3):158-65.

66. Finlay AY. Current severe psoriasis and the rule of tens. Br J Dermatol. 2005;152(5):861-7.

67. Gladman DD, Mease PJ, Krueger G, et al. Outcome measures in psoriatic arthritis. J Rheumatol. 2005;32(11):2262-9.

68. Mease PJ. Measures of psoriatic arthritis: Tender and Swollen Joint Assessment, Psoriasis Area and Severity Index (PASI), Nail Psoriasis Severity Index (NAPSI), Modified Nail Psoriasis Severity Index (mNAPSI), Mander/Newcastle Enthesitis Index (MEI), Leeds Enthesitis Index (LEI), Spondyloarthritis Research Consortium of Canada (SPARCC), Maastricht Ankylosing Spondylitis Enthesis Score (MASES), Leeds Dactylitis Index 
(LDI), Patient Global for Psoriatic Arthritis, Dermatology Life Quality Index (DLQI), Psoriatic Arthritis Quality of Life (PsAQOL), Functional Assessment of Chronic Illness Therapy-Fatigue (FACIT-F), Psoriatic Arthritis Response Criteria (PsARC), Psoriatic Arthritis Joint Activity Index (PsAJAI), Disease Activity in Psoriatic Arthritis (DAPSA), and Composite Psoriatic Disease Activity Index (CPDAI). Arthritis Care Res. 2011;63(S11): S64-S85.

69. Hawker GA, Mian S, Kendzerska T, French M. Measures of adult pain: Visual Analog Scale for Pain (VAS Pain), Numeric Rating Scale for Pain (NRS Pain), McGill Pain Questionnaire (MPQ), ShortForm McGill Pain Questionnaire (SF-MPQ), Chronic Pain Grade Scale (CPGS), Short Form-36 Bodily Pain Scale (SF-36 BPS), and Measure of Intermittent and Constant Osteoarthritis Pain (ICOAP). Arthritis Care Res. 2011;63(S11): S240-S252252.

70. Healy PJ, Helliwell PS. Measuring clinical enthesitis in psoriatic arthritis: assessment of existing measures and development of an instrument specific to psoriatic arthritis. Arthritis Rheum. 2008;59(5): 686-91.

71. Zochling J. Measures of symptoms and disease status in ankylosing spondylitis: Ankylosing Spondylitis Disease Activity Score (ASDAS), Ankylosing Spondylitis Quality of Life Scale (ASQoL), Bath Ankylosing Spondylitis Disease Activity Index (BASDAI), Bath Ankylosing Spondylitis Functional Index (BASFI), Bath Ankylosing Spondylitis Global Score (BAS-G), Bath Ankylosing Spondylitis Metrology Index (BASMI), Dougados Functional Index (DFI), and Health Assessment Questionnaire for the Spondylarthropathies (HAQ-S). Arthritis Care Res. 2011;63(S11):S47-S58.

72. Machado PMMC, Landewé RBM, van der Heijde DM. Endorsement of definitions of disease activity states and improvement scores for the Ankylosing Spondylitis Disease Activity Score: results from OMERACT 10. J Rheumatol. 2011;38(7):1502-6.

73. Knop C, Oeser M, Bastian L, Lange U, Zdichavsky M, Blauth M. Development and validation of the Visual Analogue Scale (VAS) Spine Score. Unfallchirurg. 2001;104(6):488-97.
74. Heuft-Dorenbosch L, Spoorenberg A, van Tubergen A, et al. Assessment of enthesitis in ankylosing spondylitis. Ann Rheumatic Dis. 2003;62(2): 127-32.

75. Baeten D, Sieper J, Braun J, et al. Secukinumab, an interleukin-17A inhibitor, in ankylosing spondylitis. N Engl J Med. 2015;373(26):2534-48.

76. Mease PJ, McInnes IB, Kirkham B, et al. Secukinumab inhibition of interleukin-17A in patients with psoriatic arthritis. N Engl J Med. 2015;373(14): 1329-39.

77. Blauvelt A, Prinz JC, Gottlieb AB, et al. Secukinumab administration by pre-filled syringe: efficacy, safety and usability results from a randomized controlled trial in psoriasis (FEATURE). Br J Dermatol. 2015;172(2):484-93.

78. Lacour JP, Paul C, Jazayeri S, et al. Secukinumab administration by autoinjector maintains reduction of plaque psoriasis severity over 52 weeks: results of the randomized controlled JUNCTURE trial. J Eur Acad Dermatol Venereol. 2017;31(5):847-56.

79. Paul C, Lacour JP, Tedremets L, et al. Efficacy, safety and usability of secukinumab administration by autoinjector/pen in psoriasis: a randomized, controlled trial (JUNCTURE). J Eur Acad Dermatol Venereol. 2015;29(6):1082-90.

80. Bonomo L, Abittan BJ, Hashim PW, Karki C, Mason M, Lebwohl M. Combination use of systemic therapies in psoriasis: baseline characteristics from the Corrona Psoriasis Registry. J Drugs Dermatol. 2019;18(8):731-40.

81. Mease PJ, Karki C, Liu M, et al. Discontinuation and switching patterns of tumour necrosis factor inhibitors (TNFis) in TNFi-naive and TNFi-experienced patients with psoriatic arthritis: an observational study from the US-based Corrona registry. RMD Open. 2019;5(1):e000880.

82. Mease PJ, Karki C, Liu M, et al. Baseline patient characteristics associated with response to biologic therapy in patients with psoriatic arthritis enrolled in the Corrona Psoriatic Arthritis/Spondyloarthritis Registry. RMD Open. 2018;4(1):e000638. 